\title{
Comparison of cervical characteristics assessed by TVUS (with and without saline) with digital method in prediction of labor induction outcome: a prospective study
}

\author{
Sabita Sai Chandran $^{1 *}$, Harsha Shivan ${ }^{1,2}$, Deepak Bharathi ${ }^{3,4}$, Sunita Samal ${ }^{1}$
}

\begin{abstract}
${ }^{1}$ Department of Obstetrics \& Gynecology, Mahatma Gandhi Medical College \& Research Institute, Puducherry, India ${ }^{2}$ Freelance Laparoscopic Gynecologist in Private Hospitals, Bangalore, Karnataka, India

${ }^{3}$ Department of Radiodiagnosis, Mahatma Gandhi Medical College \& Research Institute, Puducherry, India ${ }^{4}$ Department of Radiodiagnosis, Jawaharlal Institute of Postgraduate Medical Education \& Research (JIPMER), Dhanvantari Nagar, Puducherry, India
\end{abstract}

Received: 06 March 2015

Accepted: 19 April 2015

*Correspondence:

Dr. Sabita Sai Chandran,

E-mail: sabita.kutty@gmail.com

Copyright: $($ ) the author(s), publisher and licensee Medip Academy. This is an open-access article distributed under the terms of the Creative Commons Attribution Non-Commercial License, which permits unrestricted non-commercial use, distribution, and reproduction in any medium, provided the original work is properly cited.

\begin{abstract}
Background: Objective: To compare digital and transvaginal sonographic cervical assessment (pre \& post vaginal saline) in predicting the outcome of induction of labor.

Methods: Study design was prospective study, setting at medical college and research institute. Hundred pregnant women with singleton pregnancies admitted for induction of labor between 37-42 weeks of gestation. Digital and TVUS (Transvaginal ultrasonography) assessment of cervix was made with and without saline instillation and the statistical comparative data was derived. The primary outcome was initiation of active labor and the secondary outcomes were mode of delivery, active labor within 12 hours, induction to delivery interval, and the duration of active labor

Results: No ultrasound or digital cervical characteristics predicted the initiation of active labor $(\mathrm{P}>\mathrm{f} ;>0.05)$, mode of delivery and the duration of active labor; however, TVUS assessment of cervical length but not cervical width is significantly better than digital assessment of cervical length $(\mathrm{P}<0.001)$; it independently discriminates and predicts active labor within 12 hours.

Conclusions: TVUS measurement of cervical length is a better predictor of active labor within 12 hours than digital assessment. Visualization of cervix by TVUS was enhanced with saline administration but the difference between the measurements with and without saline was not statistically significant.
\end{abstract}

Keywords: TVUS, Saline, Cervical length width, Digital method, Labor outcome

\section{INTRODUCTION}

The role of cervical factors in the assessment of progress of labor has been recognized for many years. Cervical scoring systems are designed to predict the inducibility of labor and to identify women who could safely undergo induction of labor. Bishop score is the most widely and conventionally used method in assessing the cervix by digital examination. This evaluation is essentially subjective and the reliability may be affected by either inter-examiner or intra-examiner variability. It has also been demonstrated that $50 \%$ of cervical length is not palpable on digital examination due to the anatomical variation of the supravaginal part of the cervix among different individuals, whereas TVUS (Transvaginal Ultrasonography) can measure the entire cervical length 
accurately. ${ }^{1}$ TVUS assessment of cervix is more accurate and reproducible than the digital examination. ${ }^{2-5}$ In many studies it has been concluded that TVUS assessment of cervical length is a better predictor of successful induction of labor than a digitally assessed cervical length and also predicts the mode of delivery better., ${ }^{3,4,6,7}$ But some of the studies have published unfavorable results for TVUS method. ${ }^{5,8,9}$ The reason for the discrepant results may be related to the outcome variables used for analysis. Some studies showed that creating a hydroacoustic window between upper vagina and cervix by introducing sterile saline in the vagina will solve the difficulties in visualization of cervix, thus increasing the accuracy in cervical assessment. Introduction of saline is most useful in the cervical length measurements when the outer border of the cervix or external os cannot be identified easily or when cervical anatomy is distorted causing overestimation of the cervical length prior to saline instillation. ${ }^{10}$ We used a similar technique of intravaginal saline administration during TVUS to assess the cervical characteristics. We compared the predictive value of cervical characteristics assessed by TVUS (pre and post saline) with digital assessment on labor induction outcome. Our study objective was to develop a reliable method through which we can predict labour induction since we deal frequently with high risk pregnancies and hence with high rate of induction in our institute.

\section{METHODS}

Our study was prospective involving 100 cases of nullipara, with inclusion criteria of: i) 37-42 weeks of gestation ii) single live fetus in cephalic presentation with vertex as the presenting part iii) with intact membranes iv) planned for induction of labor by prostaglandins. The cases with history of previous operations of cervix and uterus were excluded. This study was approved by the institute ethical committee. On admission to the labor ward a detailed history was recorded and thorough clinical evaluation was done; period of gestation and indication for induction of labor were confirmed again. Digital examination was performed to assess the cervix. Sonographic assessment of cervix was performed by a sonologist who was blinded to the digital cervical assessment and the clinical history. The outcome was categorized as primary and secondary in the study for analysis.

The primary outcome is obtained in terms of comparison between pre-saline and post-saline cervical assessment by TVUS and digital assessment with respect to the following secondary outcome:

i. Frequency of initiation of active labor,

ii. Frequency of active labor within twelve hours of induction,

iii. Duration of active labor,

iv. Interval between induction and delivery

v. Mode of delivery.
Active labor is defined as regular painful uterine contractions with interval of two to three minutes and the cervix dilated to three centimeters with $80 \%$ of effacement. Failed induction is defined as the failure to initiate active labor with two doses of intracervical prostaglandin E2 gel instilled twelve hours apart.

Patients were placed in lithotomy position with pillow under the gluteal region and the ultrasound probe was placed in the vagina approximately three centimeters away from the cervix to avoid any distortion of the shape or position of the cervix. A midline sagittal view of the cervix with echogenic endocervical mucosa along the length of cervical canal was obtained. Cervical length, width and presence of funneling was assessed and the same were measured after instilling $20 \mathrm{ml}$ of sterile normal saline through an infant feeding tube of size $9 \mathrm{~F}$ introduced into the vagina alongside the probe. The cervical length was measured between the internal and external os and the cervical dilatation was defined as the maximum width of the echolucency across the endocervical canal. Presence of funneling was defined as $\mathrm{V}$ or $\mathrm{U}$ shaped indentation of the internal os and the measurement was made from the apex of the funnel to the plane of the internal os. After assessing the cervix, the induction of labor was performed with prostaglandin E2 gel in all cases of the study group.

\section{Statistical analysis}

The dependent variables for Receiver Operator Characteristics (ROC) curve were initiation of active labor, mode of delivery, active labor within 12 hours and induction to delivery interval within 24 hours. The cervical length and width by digital assessment and the same parameters and funneling measured with TVUS in pre-saline and post-saline phases were the independent variables. The mean, standard deviation and range of values are presented for continuous variables and frequency distributions for categorical variables. We used a pair-wise correlation test to check the correlation between values obtained by digital method and TVUS. Pair-wise correlation was also used to check the correlation between values obtained by pre-and-post saline TVUS. A correlation coefficient closer to 1 indicates good positive correlation and a correlation coefficient closer to 0 indicates good negative correlation. The ability of cervical length and cervical width obtained by digital and TVUS methods, to predict and discriminate initiation of active labor, mode of delivery, active labor within 12 hours, induction to delivery interval within 24 hours and the duration of active labor, were ascertained using analysis of variance (ANOVA) test and ROC curves. A $\mathrm{P}>\mathrm{f}$ of less than 0.05 in the ANOVA was considered statistically significant. The Area under ROC and the $95 \%$ confidence intervals around the area under ROC were estimated. The area under ROC was used to compare digital and TVUS values and to determine the better predictor. An area under ROC, closer to one was considered as better for predictors whereas the value less 
than 0.7 as not good. The sensitivity, specificity and cutoff values were assessed for the tests that showed a good area under ROC.

\section{RESULTS}

The total number of cases studied were 100 of the age $23.9 \pm 4.7$ years (mean \pm SD) and the mean gestational age at induction was 40 weeks. Digital and transvaginal ultrasonographic assessments of cervix were performed to predict the labor induction outcome. The most common indication for induction of labor was oligohydramnios (55/100) followed by post-term pregnancy (22/100) and gestational hypertension
(16/100). The mean cervical length (Digi cl) and width (Digi w), by digital assessment were $1.7 \mathrm{~cm}$ (range $0.5-3$ $\mathrm{cm}$ ) and $0.49 \mathrm{~cm}$ (range $0-2 \mathrm{~cm}$ ) respectively; the corresponding measures by TVUS during presaline status were (Pre cl) $2.84 \mathrm{~cm}$ (range 1.3-6.4 cm) and (Pre w) $0.11 \mathrm{~cm}$ (range $0-1.8 \mathrm{~cm}$ ). The onset of active labor occurred in $82 \%$ of the cases whereas $58 \%$ had active labor within 12 hours of induction. The mean duration of active labor was 3.78 hours (range 1.15-16.07 hours). The mean duration of induction to delivery interval was 16.15 hours (range 4.11-42.12 hours). Vaginal delivery was performed in $72 \%$ of the cases which included 8 cases of instrumental delivery but $28 \%$ required cesarean section mostly (23 out of 28 ) for fetal distress.

Table 1: Analysis of variance (ANOVA) test.

\begin{tabular}{|c|c|c|c|c|c|}
\hline Outcome & Number & Variables & df & F & $P>f$ \\
\hline \multirow{6}{*}{$\begin{array}{l}\text { Initiation of active } \\
\text { labor }\end{array}$} & \multirow{6}{*}{$\begin{array}{l}\text { Initiated } 82 \\
\text { No } 18\end{array}$} & Digi cl & \multirow{6}{*}{99} & 1.70 & 0.1956 \\
\hline & & Pre cl & & 1.43 & 0.2354 \\
\hline & & Post cl & & 2.12 & 0.1485 \\
\hline & & Digi w & & 0.17 & 0.6821 \\
\hline & & Pre w & & 0.53 & 0.4695 \\
\hline & & Post w & & 0.56 & 0.4577 \\
\hline \multirow{6}{*}{ Mode of delivery } & \multirow{6}{*}{$\begin{array}{l}\text { Vaginal } 72 \\
\text { Caesarean } 28\end{array}$} & Digi cl & \multirow{6}{*}{99} & 0.13 & 0.7153 \\
\hline & & Pre cl & & 3.91 & 0.0509 \\
\hline & & Post cl & & 2.97 & 0.0878 \\
\hline & & Digi w & & 0.91 & 0.3417 \\
\hline & & Pre w & & 0.9432 & 0.9432 \\
\hline & & Post w & & 0.9272 & 0.9272 \\
\hline \multirow{6}{*}{$\begin{array}{l}\text { Active labor within } \\
12 \text { hours }\end{array}$} & \multirow{6}{*}{$\begin{array}{l}\text { Yes } 58 \\
\text { No } 42\end{array}$} & Digi cl & \multirow{6}{*}{99} & 9.02 & 0.0034 \\
\hline & & Pre cl & & 76.45 & 0.0000 \\
\hline & & Post cl & & 108.64 & 0.0000 \\
\hline & & Digi w & & 1.46 & 0.2295 \\
\hline & & Pre w & & 0.02 & 0.8860 \\
\hline & & Post w & & 0.03 & 0.8560 \\
\hline \multirow{6}{*}{$\begin{array}{l}\text { Induction delivery } \\
\text { Interval with cut } \\
\text { off } 24 \text { hours }\end{array}$} & \multirow{6}{*}{$\begin{array}{l}\text { Yes } 64 \\
\text { No } 8\end{array}$} & Digi cl & \multirow{6}{*}{71} & 11.75 & 0.0010 \\
\hline & & Pre cl & & 18.65 & 0.0001 \\
\hline & & Post cl & & 18.64 & 0.0001 \\
\hline & & Digi w & & 5.54 & 0.0614 \\
\hline & & Pre w & & 0.12 & 0.7324 \\
\hline & & Post w & & 0.11 & 0.7399 \\
\hline \multirow{6}{*}{$\begin{array}{l}\text { Duration of active } \\
\text { labor }\end{array}$} & \multirow{6}{*}{$\begin{array}{l}<4 \text { hours } \\
>4 \text { hours }\end{array}$} & Digi cl & 81 & 0.47 & 0.4948 \\
\hline & & Pre cl & \multirow{5}{*}{99} & 0.32 & 0.5720 \\
\hline & & Post cl & & 0.14 & 0.7046 \\
\hline & & Digi w & & 0.05 & 0.8266 \\
\hline & & Pre w & & 1.14 & 0.2888 \\
\hline & & Post w & & 1.26 & 0.2659 \\
\hline
\end{tabular}

df: Degrees of freedom, P>f: Probability more than f, cl - Cervical length, w - Cervical width, Pre - Presaline, Post - Post saline, Digi - Digital assessment 
Table 2: Correlation of presaline, postsaline and TVUS values and correlation of digital and TVUS values.

\begin{tabular}{|lc|}
\hline Correlation of presaline and postsaline TVUS values \\
\hline Pre cl, Post cl correlation & 0.95 \\
\hline Pre w, Post w correlation & 1.00 \\
\hline Prefunnnel, postfunnel correlation & 1.000 \\
\hline Correlation of digital and TVUS assessments & \\
\hline Digi cl, Pre cl correlation & 0.26 \\
\hline Digi cl, Post cl correlation & 0.25 \\
\hline Digi w, Pre w correlation & 0.32 \\
\hline Digi w, Post w correlation & 0.33 \\
\hline
\end{tabular}

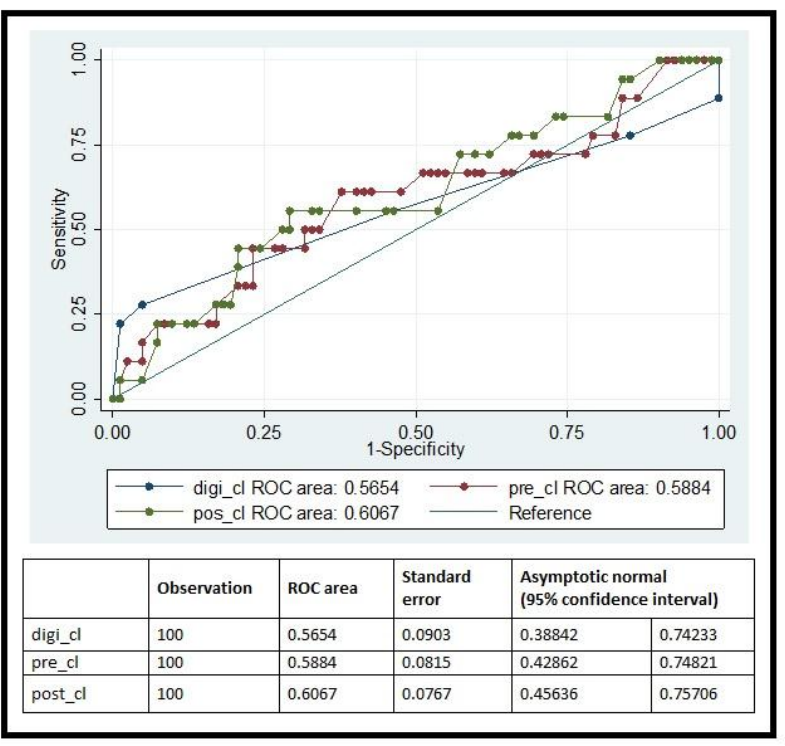

Figure 1: ROC curve of cervical width by digital and TVUS assessment with initiation of active labor.

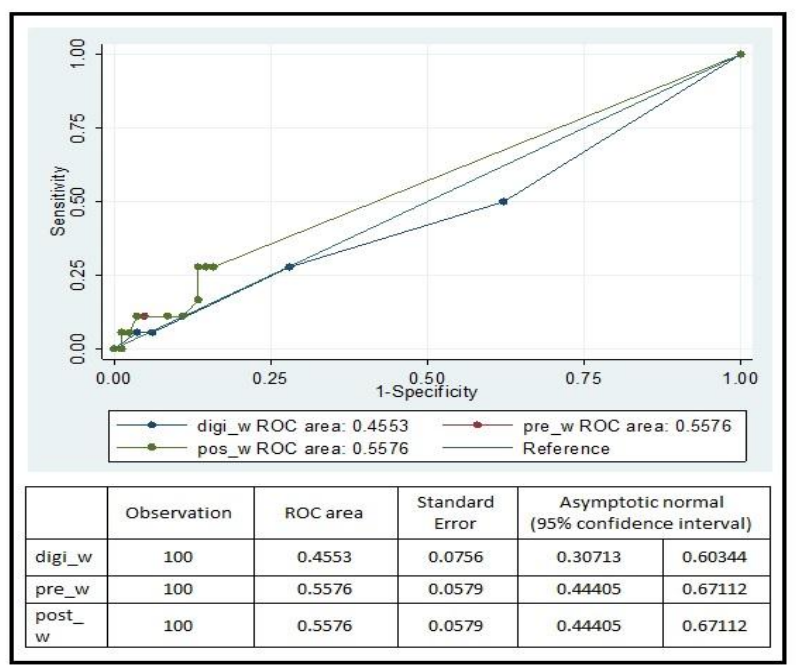

Figure 2: ROC curve of cervical length by digital and TVUS assessment with the mode of delivery.

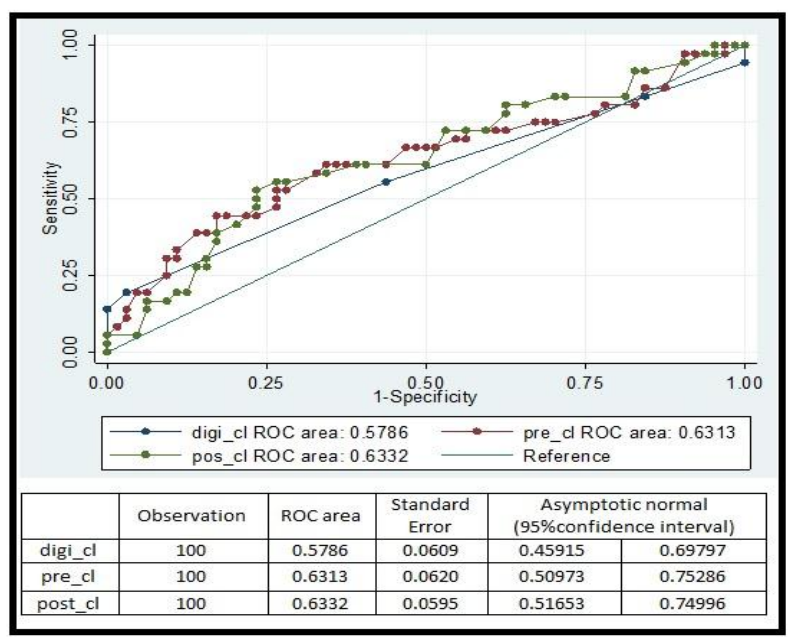

Figure 3: ROC curve of cervical width by digital and TVUS assessment with the mode of delivery.

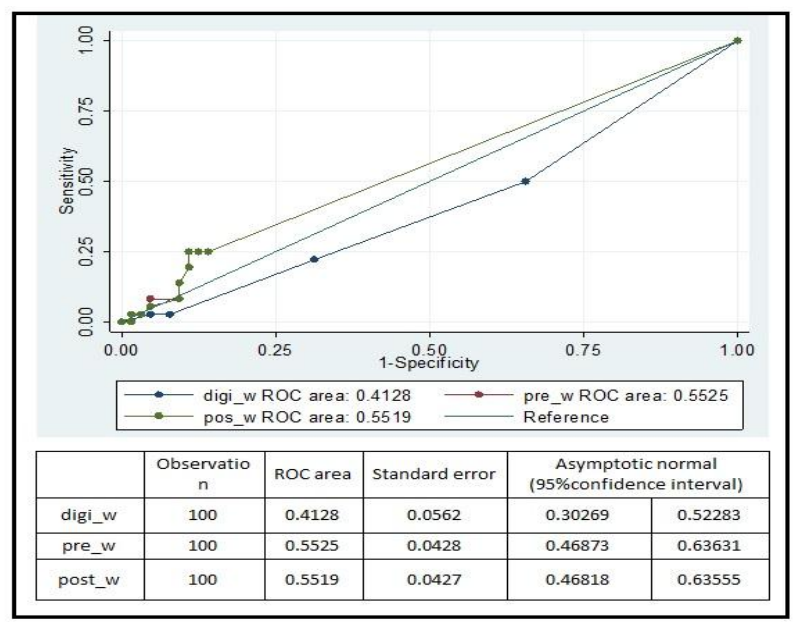

Figure 4: ROC curve of cervical length by digital and TVUS assessment with active labour within 12 hours.

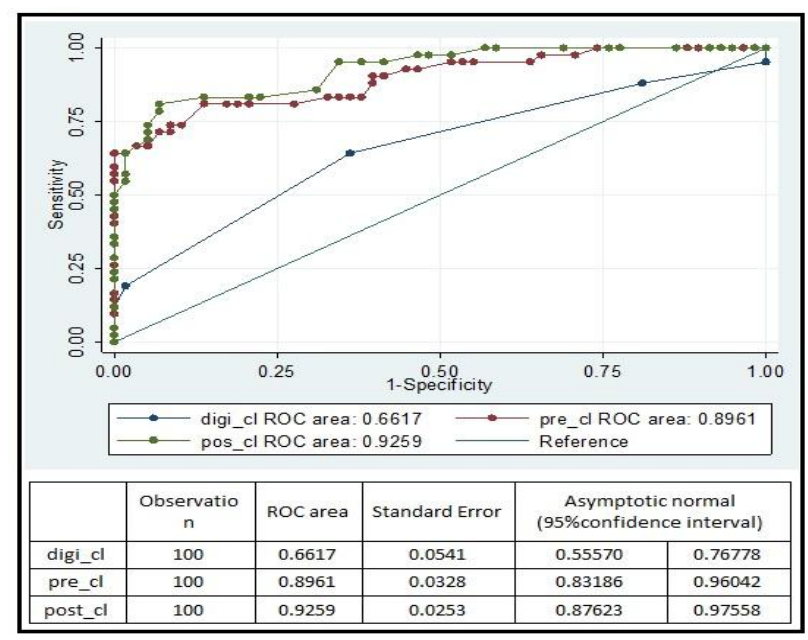

Figure 5: ROC curve of cervical width by digital and TVUS assessment with active labor within 12 hours. 


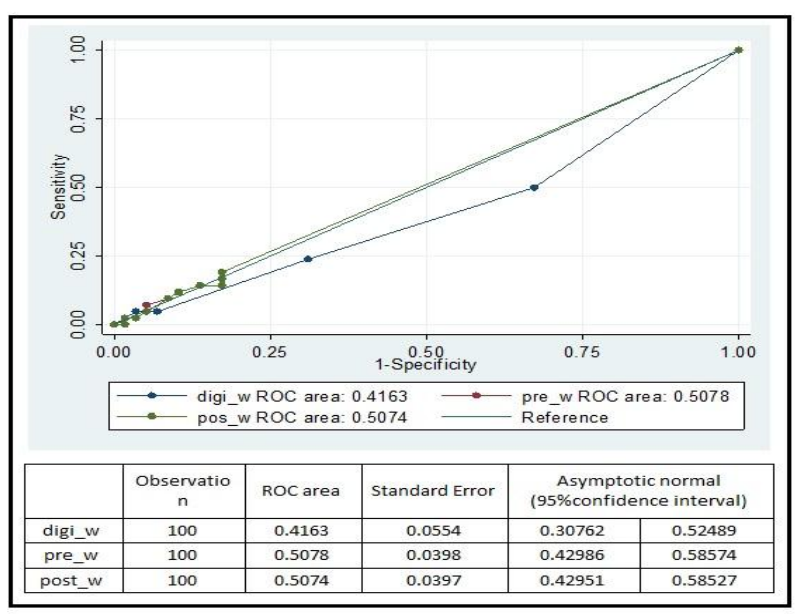

Figure 6: ROC curve of cervical length by digital and TVUS assessment with induction to delivery interval within 24 hours.

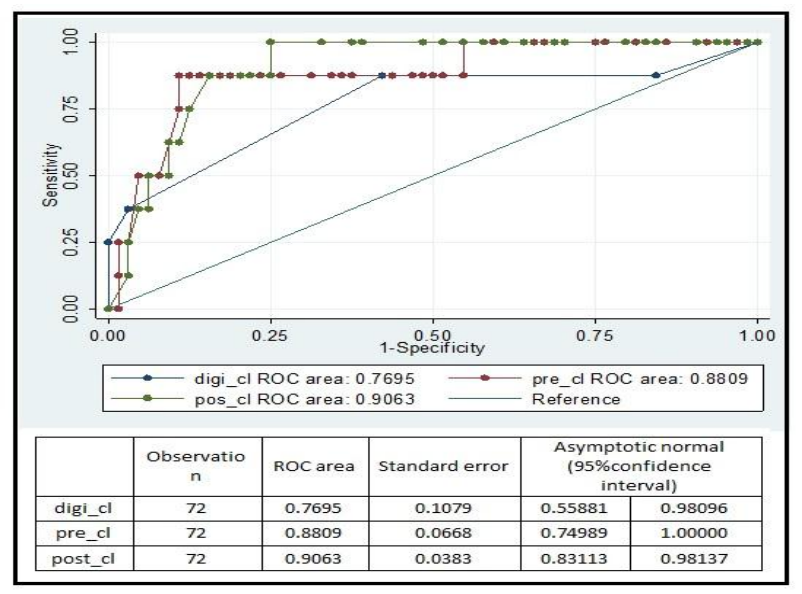

Figure 7: ROC curve of cervical width by digital and TVUS assessment with induction to delivery interval within 24 hours.

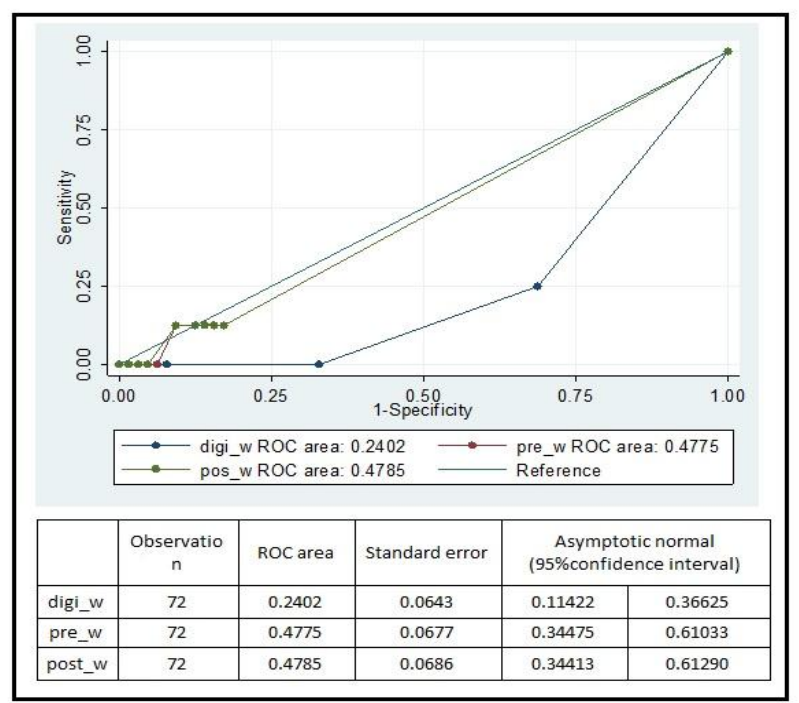

Figure 8: Pre-saline TVUS assessment of cervix.

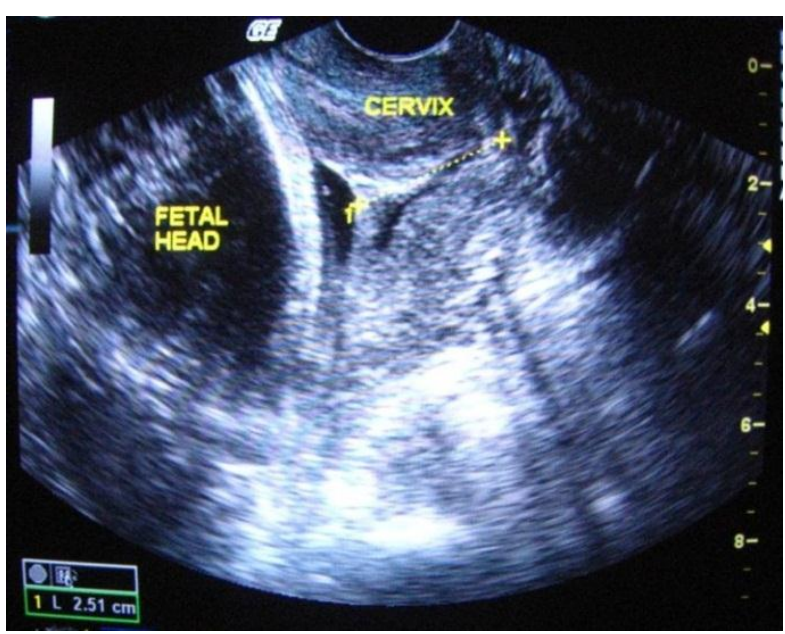

Figure 9: Pre-saline TVUS assessment of cervix.

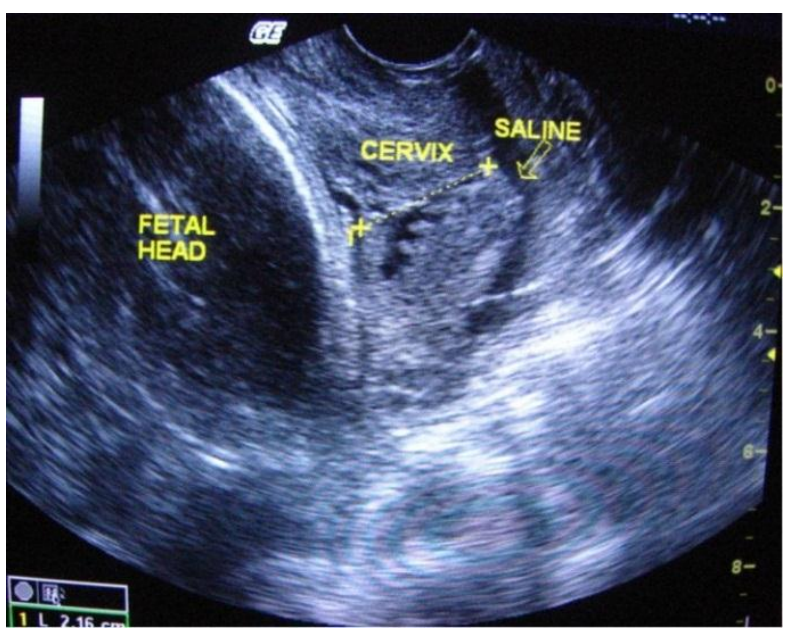

Figure 10: Post-saline TVUS assessment of cervix.

\section{DISCUSSION}

\section{Main findings}

Gross differences were observed between the cervical dimensions obtained by digital method and TVUS method; but the saline instillation during TVUS made no significant difference in the values obtained prior to its instillation. All three methods (presaline TVUS, postsaline TVUS and digital method) were poor to predict the initiation of active labor (Figure 1 and 2) as well as the mode of delivery overall (Figure 3 and 4).

The cervical length assessed by pre-saline and post-saline TVUS were significantly better than digital assessment $(\mathrm{P}$ $<0.001$ ) in predicting active labor within 12 hours (Figure 5 ); but the cervical width assessment showed none of the three methods being predictive of active labor within 12 hours $(\mathrm{P}=0.27)$ (Figure 6$)$. TVUS measurements of cervical length as well as width are better than the digital assessment in predicting the induction to delivery interval within 24 hours, though the difference is not statistically significant (Figure 7 and 8 ). 


\section{Strength and limitations}

The strength of the study includes the selection criteria which included only the nulliparous women and hence parity as a confounding factor was avoided. Moreover, to maintain uniformity, all the subjects were induced with PGE2 gel. The sonologist was also made blind to the clinical findings to avoid bias. Whereas, in other studies they have included both nulliparous and multiparous women; the method of induction was not uniformly maintained. ${ }^{2,4-6}$ The limitation of the study includes the smaller sample size requiring further studies in large number of subjects for confirmation.

\section{Interpretation}

TVUS has gained increasing applications in obstetrics. In this regard transvaginal ultrasound characteristics of cervix, particularly cervical length, have been found to be predictive of impending delivery ${ }^{11}$. The use of delivery mode as an outcome variable obviously affects the results because this parameter is influenced by number of factors, such as birth weight, maternal stature, indications for cesarean delivery and the rate of cesarean delivery performed in an institution. Ware and Raynor ${ }^{4}$ found a cut-off point of $3 \mathrm{~cm}$ for sonographic cervical length as the best predictor of vaginal delivery. Ware and Raynor ${ }^{4}$ also concluded that sonographic cervical length and parity were the independent predictors of mode of delivery; in a multicenter study, Pandis et al. ${ }^{6}$ found that cervical length provided a significant contribution in prediction of vaginal delivery within 24 hours. Gabriel et al ${ }^{7}$ concluded that even in the subset of unfavorable bishop score, sonographic cervical length $<26 \mathrm{~mm}$ is associated with a lower risk of cesarean delivery and a shorter duration of labor. But our study showed that neither cervical length nor its width predicted the mode of delivery (Figure 3, 4 and Table 1).

Watson et al. ${ }^{8}$ reported that cervical dilatation by digital assessment was a predictor of induction success. But in our study, TVUS assessment of cervical length was significantly better than digital assessment of cervical length ( $\mathrm{P}<0.001)$ which predicted active labor within 12 hours but such correlation was not found with cervical width measurements (Figure 5, 6 and Table 1). A cutoff value of $2.9 \mathrm{~cm}$ of cervical length obtained by presaline TVUS has a sensitivity of $81 \%$ and specificity of $86 \%$ and can typify $84 \%$ of cases as a subset who will go into active labor within 12 hours. A cut-off value of $2.71 \mathrm{~cm}$ of cervical length obtained by postsaline TVUS has a sensitivity of $80.9 \%$ and specificity of $93.1 \%$ and can typify $88 \%$ of cases as a subset who will go into active labor within 12 hour. Hence there is a very good correlation between the presaline and postsaline TVUS values, but the correlation between digital and TVUS assessment values was poor.

Chandra et al. ${ }^{5}$ found that no ultrasound characteristic predicted active labor within 12 hours; instead maternal weight, cervical dilatation and cervical effacement independently predicted active labor within 12 hours. Ware and Raynor ${ }^{4}$ also found that both sonographically measured cervical length and bishop score predicted induction to delivery interval, whereas, others ${ }^{2,3,5,8,9}$ found unfavorable results. Yang et al. ${ }^{12}$ found that parity was the only independent predictor of the duration of labor; neither cervical length by TVUS nor the Bishop score was significantly predictive for the duration of labor.

In our study, the mean duration of active labor was 3.78 hours (range 1.15-16.07 hours); the cervical length obtained by TVUS and digital assessment predicted the induction to delivery interval within 24 hours (Table 1); in this context, the TVUS method was found to be better than digital assessment but the difference was not statistically significant $(\mathrm{P}=0.15)$, (Figure 7). Whereas, cervical width did not predict the induction to delivery interval within 24 hours as the area under the ROC curves for both falls below 0.5 (Figure 8) irrespective of whether assessed by TVUS or digitally.

None of the variables like cervical length or cervical width either digitally or by TVUS predicted the duration of active labor ( $P>f>0.05$ ) (Table 1). These findings suggest that once active labor begins, the progression of labor largely depends on factors other than cervical status.

Though visualization of cervix by TVUS was enhanced following saline administration, the average difference between presaline and postsaline cervical length measurement being $0.19 \mathrm{~cm}$, was not statistically significant (Figure 10, 11 and Table 2). The TVUS examination was tolerated by the pregnant women and there were no complications related to this procedure.

The other independent variables in our study like cervical consistency and position by digital assessment had no significant association with initiation of active labor, mode of delivery, active labor within 12 hours, induction to delivery interval within 24 hours and the duration of labor. Similar findings were noted in the previous studies. ${ }^{2,3,5-9,13}$ However, Chandra et al. ${ }^{5}$ found that cervical position was independently associated with the latent phase of labor. As there were only 5 patients with funneling, we could not explore further on its statistical analysis and significance.

\section{CONCLUSION}

TVUS method of cervical length but not width is more objective, quantitative and reproducible than the digital method in predicting the active labor within 12 hours and also the induction to delivery interval within 24 hours and both cervical length and breadth measured by any of these methods predicted the mode of delivery and duration of active labor. Though visualization of cervix by TVUS was enhanced following saline administration, the difference between presaline and postsaline cervical length measurement was not statistically significant. 
Funding: No funding sources

Conflict of interest: None declared

Ethical approval: The study was approved by the institutional ethics committee

\section{REFERENCES}

1. Jackson GM, Ludmir J, Badir TJ. Accuracy of digital examination and ultrasound in the evaluation of cervical length. J Obstet Gynecol. 1992;79:214-8.

2. Paterson-Brown S, Fisk NM, Edmonds DK, Rodeck $\mathrm{CH}$. Pre-induction cervical assessment by Bishop's score and transvaginal ultrasound. Eur J Obstet Gynecol Reprod Biol. 1991;40:17-23.

3. Boozarjomehri F, Timor-Tritsch I, Chao CR, Fox HE. Transvaginal Ultrasonographic evaluation of cervix before labor: presence of cervical wedging is associated with shorter duration of induced labor. Am J Obstet Gynecol. 1994;171:1081-7.

4. Ware, Raynor. Transvaginal ultrasonographic cervical measurement as a predictor of successful labor induction. Am J Obstet Gynecol. 2000 May;182(5):1030-2.

5. Chandra S, Crane JM, Hutchens D, Young DC. Transvaginal Ultrasound and digital examination in predicting successful labor induction. Obstet Gynecol. 2001;98:2-6.

6. Pandis GK, Papageorghiou AT, Ramanathan VG, Thompson MO, Nicolaides KH. Pre-induction sonographic measurement of cervical length in the prediction of successful induction of labour. Ultrasound Obstet Gynecol. 2001;18:623-8.
7. Gabriel R, Darnaud T, Chalot F, Gonzalez N, Leymarie F, Quereux C. Transvaginal sonography of the uterine cervix prior to labor induction. Ultrasound Obstet Gynecol. 2002 Mar;19(3):254-7.

8. Watson WJ, Stevens D, Welter S, Day D. Factors predicting successful induction of labor. Obstet Gynecol. 1996;88:990-2.

9. Gonen R, Degani S, Ron A. Prediction of successful induction of labor: comparison of Transvaginal Ultrasound and Bishop score. Eur J Ultrasound. 1998;7:183-7.

10. Elghorori MRM, Hassan I, Morris E, Frazer D. Intravaginal hydrosonography and cervical length assessment in pregnant women before induction of labor: a modified technique. J Obstet Gynecol. 2005 Jul;25(5):435-9.

11. Crane JMG, Van den Hof M, Armson BA, Liston R. Transvaginal ultrasound in the prediction of preterm delivery: singleton and twin gestations. Obstet Gynecol. 1997;90(3):357-63.

12. Yang SH, Roh CR, Kim JH. Transvaginal ultrasonography for cervical assessment before induction of labor. J Ultrasound Med. 2004 Mar;23(3):375-82.

13. Harrison RF, Flynn M, Craft I. Assessment of factors constituting an 'inducibility profile'. Obstet Gynecol. 1977;49(3):270-1.

DOI: $10.18203 / 2320-1770$. ijrcog20150065

Cite this article as: Chandran SS, Shivan $\mathrm{H}$, Bharathi D, Samal S. Comparison of cervical characteristics assessed by TVUS (with and without saline) with digital method in prediction of labor induction outcome: a prospective study. Int J Reprod Contracept Obstet Gynecol 2015;4:634-40. 